\title{
New trends in the health care provision for people with learning disabilities: a Welsh paradigm
}

\author{
H. M. Verma
}

The launch of the All Wales Strategy for people with learning disabilities in 1983 heralded an era of redressing the anomaly of $80 \%$ of resources being deployed in hospitals while the majority of people with learning disabilities lived at home (Welsh Office, 1983). Social services were given the lead responsibility to plan and co-ordinate services away from institutions towards community based facilities. In 1983 , some 2,100 people with a learning disability were resident in hospitals and hostels; by April 1991 the number had fallen to just over 1,300. There was a concomitant development of services in the community with a rise in the number of adults living in ordinary accommodation from 170 to 1,000. The priorities for development of services in the second phase of the strategy were set out in the 'Framework for Development' from April 1992 (Welsh Office, 1993).

One of the main priority areas is the resettlement of the remaining hospital residents into the community. However desirable the integration of disabled people into ordinary society, if they disappear from view they are likely to be ignored in the provision of the special help they need (Fryers, 1991).

\section{Health gain needs}

People with a learning disability are known to experience the same health problems as the general population but they may be affected by a greater variety and number, with increased frequency. Ill health in these people is often obscured by their impairment and uptake of health care and reporting of illness is low (Howells, 1986; Howells \& Barker, 1990). In addition they have medical conditions associated with the underlying impairment.
Alzheimer's disease is almost universal in Down's syndrome. As many as $30-40 \%$ of people with learning disability have refractive errors; this rises to $75 \%$ among people with a severe learning disability. Up to $60-70 \%$ have measurable hearing loss; $18 \%$ have two sensory impairments; $60 \%$ have speech and language impairment problems. One in three children with a severe learning disability have a history of epilepsy. Other prevalent specific co-morbidity includes cardiac abnormalities, leukaemia and hypothyroidism, mobility problems, incontinence, fractures, weight problems, dental hygiene, respiratory and skin problems.

There is a greater risk of developing mental health problems, with an overall prevalence between 20\%-40\%. Exposure to the routine stresses of life in a community setting is likely to precipitate a variety of psychiatric conditions. Court diversion schemes would result in more offenders receiving help in the community thereby putting extra demands on the local services, including health. Improved life expectancy will bring an increase in agerelated physical and mental illness (Dupont \& Mortensen, 1991). In a traditional institutional set-up, the majority of these health needs were dealt with by the hospital medical staff with 24 hour cover. With the move into the community, in widely dispersed settings, the health care needs of this group presents a significant challenge.

Concern has been expressed over the uncertainty that exists among general practitioners about the roles and functions of certain services (Bernard \& Bates, 1994). Frequent failure to deliver an appropriate level of medical care and the merit of regular screening, preferably by a suitably trained member of staff have been highlighted (Wilson et al, 1990). Even where the primary 
care team is managing the health needs adequately, yawning service gaps were identified for clients with conditions requiring home treatment on an ongoing basis (Minihan \& Dean, 1990). There is a growing fear that with the moving out from institutions the specialist medical knowledge is also disappearing.

\section{Protocol for health gain}

In July, 1990 the Secretary of State for Wales endorsed the following strategic intent: "Working with others, the NHS aim to take the people of Wales into the 21 st century with a level of health on course to compare with the best in Europe". To achieve this ambitious goal, the service has espoused three principles: health gain focused, people centred, and resource effective.

At district level this will be pursued through the local strategles for health. In order to help the board members of trusts, the district health authorities (DHAs) and the family health service authorities (FHSAs) to develop their local strategies for health, expert advice on the planning of health services is given through protocols for investment in health gain in various specialities. The Protocol for Investment in Health Gain for People with Learning Disabilities is one of these. It is a trendsetter in its own right, providing a service model in the new NHS culture.

The protocol is strategic, knowledge-based and has advisory roles. It identifies areas where further investment could bring worthwhile health gain and indicates where reinvestment could be considered. It assists trusts, DHAs and FHSAs in focusing on key issues by assessment of current and future circumstances at district level, taking into consideration the age, gender, racial backgound and language of individuals. It highlights some important future trends, for example, within five years. HIV infection is projected to become the largest infectious cause of learning disability. The protocol sets out 11 health gain targets ranging from sensory, physical, emotional and psychiatric morbidity to reducing morbidity among carers. There are 14 service targets with emphasis on inter-agency partnership between health, social services and local education authority. The DHAs, FHSAs and other purchasers, through their service specification, are notably exhorted to ensure that all children under 5 suspected of having learning disability have a comprehensive and multidisciplinary development and physical assessment, that there is agreed policy on early counselling and sensitive disclosure of diagnosis and to ensure that there is a seamless transition of care from child to adult, adult to elderly and hospital to community.

There is emphasis on a primary care team approach involving the GP and community services, preventing expensive calls on more specialised care. There are service targets to ensure that GPs have the names of the keyworker/care manager for each person. The district health authorities, through service specification, will ensure that people with Down's syndrome have a yearly thyroid function test and that yearly health consultation is offered to people with learning disability and their relatives or carers. The needs of people with learning disabilities and superimposed psychiatric illness, challenging or offending behaviours and other special needs are emphasised with specific acute admission and long-stay bed requirements. The opportunity for people to use mainstream acute services is encouraged and the importance of multiagency co-operation in ongoing individual plans highlighted.

Opportunities for health gain across the levels of care, ranging from prevention, promotion and support are also highlighted. A table indicates the clinical effectiveness of interventions that increase health gain and those which should be abandoned. There is cross-reference to other protocols, as on oral health and physical and sensory disability.

It is assumed that only minimal additional funds will be required. Reallocation of resources over time with the help of audit, in particular transfer of funds from health authority to local authorities, will meet some of the targets.

\section{Comment}

The protocol sets a tall order for addressing the health needs of a very vulnerable client group. There is a need to gauge GP' attitudes and commitment towards ascertaining baseline information for achieving health targets and issues related to regular screening. The skills and resources in the primary care teams need to develop further to face the challenge of coping with highly complex and demanding health problems. Distance learning modules 
have been arranged for the GPs in collaboration with the University of Swansea. The course package was sent to all practices in Wales and 20 practices have taken it up. The health authorities have a special responsibility to safeguard the interests of this group because the monies released from closure of hospitals do not always follow the clients (Glover et al, 1993). All the counties in Wales now have local strategies for health in place. Despite the present culture of NHS reforms with market forces shaping the pattern in health care delivery, the needs of this client group are incorporated adequately in local plans. The Welsh Office, however, needs to be vigilant and, if necessary, adopt a more directive approach to ensure that the momentum does not get lost with time. The report of the eight county meeting to determine progress on service provision for adults with mental handicap with superimposed challenging behaviour and/or mental illness and who require specialist health services testifies to this commitment (Welsh Office, 1994).

The NHS in Wales aims to add years to life and life to years and The Protocol for People with Learning Disabilities will play a pivotal role in achieving this aim. It has been widely acclaimed in many European countries and undoubtedly offers a model for the rest of the UK

\section{Acknowledgements}

My thanks to Professor W. I. Fraser for his comments and to Ann Evans for her help.

\section{References}

BERNARD. S. \& BATES. R. E. (1994) the role of the psychiatrist In learning disability. Psychiatric Bulletin, 18, 205-206.

DUPONT, A. \& MORTENSEN, P. B. (1991) Avoldable death in a cohort of severely mentally retarded. In Key Issues in Mental Retardation Research (W. Fraser). Routledge.

FrYers, T. (1991) Public health approaches to mental retardation: handicap due to intellectual impairment. In Oxford Textbook of Public Health. Oxford: Oxford University Press.

GLOVER, G. R., ROHDE, J. \& FARMER, R. D. (1993) Is the money following the clients with learning disabilities? British Medical Journal, 306, 987-990.

Howeus, G. (1986) Are the medical needs of mentally handicapped people being met? Journal of the Royal College of General Practitioners, 36, 429-435.

- \& BARKER, M. (1990) Primary Care of People with Mental Handicap. Occasional paper 47. London: The Royal College of General Practitioners.

Minihan, P. M. \& DEAN, D. H. (1990) Meeting the needs for health services of persons with mental retardation living in the community. American Journal of Public Health. 80. 1043-1048.

WILSON D. N. et al (1990) Health care screening for people with mental handicap living in the community. British Medical Joumal, S01, 1379-1381.

WELSH OFFICE (1983) The All Wales Strategy for the Development of Services for Mentally Handicapped People.

- (1993) The Protocol for Investment in Health Gain for People with Learning Disability.

- (1994) Challenges and Responses: a report of 8 County Meetings on progress on specialist health services for adults with mental handicap who display challenging behaviour.

H. M. Verma, Consultant Psychiatrist, Brynhyfryd Hospital, Forden, Near Welshpool, Powys SY21 8NW 